\title{
DOMESTICANDO EL DESIERTO. MEDIO AMBIENTE Y OCUPACIONES HUMANAS EN RAMADITAS, DESIERTO DE ATACAMA
}

\author{
TAIMING THE DESERT. ENVIRONMENT AND HUMAN OCCUPATIONS \\ IN RAMADITAS, ATACAMA DESERT
}

\author{
Mario A. Rivera* y Justin P. Dodd ${ }^{* *}$
}

\begin{abstract}
El sitio arqueológico de Ramaditas tiene un significado más allá de su valor histórico-social y ambiental. Localizado en uno de los desiertos más áridos y antiguos del mundo, el desierto de Atacama, Ramaditas representa un reto al entendimiento actual de la importancia del agua como recurso de sustento y desarrollo humano en cualquier lugar. Bajo estas condiciones es difícil explicar cómo las sociedades prehispánicas lograron asentarse y prosperar en un medio de tal hostilidad. Estudios previos realizados en diversas zonas del desierto de Atacama, y en especial en las áreas de Guatacondo y Tarapacá, demuestran que han sido dramáticamente más productivas en el pasado. El hecho que las sociedades hayan podido desarrollarse en estos ambientes y mantener niveles demográficos más altos que los actuales requieren de una explicación.

El área de Ramaditas/Guatacondo exhibe importantes evidencias de ocupación humana que se manifiestan en conjuntos arquitectónicos concentrados en dos aldeas principales, extensos campos de cultivos y rasgos tales como reservorios de agua, pequeños tranques, pozos artesianos, una extensa red de canales y dispositivos para controlar el flujo del agua. El área es importante tanto desde el punto de vista climatológico como arqueológico, debido a que se ubica gran cantidad de artefactos y uso de la tierra con prácticas agrícolas que estaban en pleno desarrollo hace 2500 años. En este trabajo entregamos recientes resultados en relación con las condiciones paleoambientales del área obtenidos a través de estudios dendrocronológicos que favorecen un modelo paleoclimático a nivel macrofísico basado en índices de precipitaciones en la alta cordillera y el subsecuente escurrimiento de aguas hacia la Pampa del Tamarugal.
\end{abstract}

Palabras claves: desierto de Atacama, dendrocronología, paleoambiente, Ramaditas.

The archaeological site of Ramaditas has a meaning that goes beyond its historic-social and environmental value. Settled in the world driest and perhaps oldest desert, the Atacama Desert, the site is challenge to current understanding of what water means as a resource for human sustainability any where in the world. Under these conditions, it is difficult to explain how prehispanic society was able to settle and prosper in such hard environment. Previous research, especially in Guatacondo and Tarapaca regions, demonstrates that these societies have been extremely productive in past times. The fact that these groups were able to develop themselves in such hard environments maintaining higher demographic levels than todays demand an explanation.

The archaeological area of Ramaditas contains important architectonic compounds grouped in two main villages, extended relicts of agricultural fields including artesian wells, reservoirs, and complex networks of canal irrigation. The area is important both from a climatologically view point as well as archaeologically because the assemblage indicates people were practicing full agriculture 2500 ago. In this paper I provide new data in relation to paleoenviroment of the area steaming from dendrochronology research that favors a macrophysics' paleoclimatic model based on precipitation data from the surrounding highlands and its subsequent water runoff towards Pampa Tamarugal.

Key words: Atacama desert, dendrochronology, paleoenvironment, Ramaditas.

\section{El área arqueológica de Ramaditas}

\section{Introducción}

El proyecto Ramaditas es parte de un programa mayor diseñado como un esfuerzo para estudiar cómo las culturas reaccionan a las perturbaciones del medio ambiente. Nuestra motivación se origina al momento de conocer acerca de las condiciones medioambientales que han predominado cuando la aldea de Ramaditas fue originalmente ocupada 2600 años antes de esta era. Tres objetivos dominan nuestra propuesta, a saber:

(a) La naturaleza de la adaptación humana en los últimos tres mil años en este medio ambiente tan árido,

\footnotetext{
* Universidad de Magallanes, MINEDUC, Director Ejecutivo, Programa Identidad del Fin del Mundo, Chile. Correo electrónico: marivera41@gmail.com

** Northern Illinois University, Department of Geology and Environmental Geosciences, Estado Unidos. Correo electrónico: jdodd@niu.edu
} 
(b) los patrones de migración humana a lo largo de los valles andinos meridionales $y$,

(c) los patrones agrícolas del uso de la tierra y su abandono en los valles y oasis del desierto de Atacama.

Más allá de su valor histórico-social el sitio arqueológico de Ramaditas tiene un significado crítico desde el punto de vista ambiental. Localizado en uno de los parajes más secos, desprovistos y antiguos del mundo, el desierto de Atacama, Ramaditas representa un reto al entendimiento actual de la importancia del agua como recurso de sustento y desarrollo humano en cualquier lugar.

El desierto de Atacama es el más árido del planeta y por tanto el acceso al agua es vital para la existencia de población humana. Actualmente la región recibe no más de $5 \mathrm{~mm}$ de precipitación media anual, complementado por avenidas estacionales y napas subterráneas alimentadas por recarga del vital elemento en la alta cordillera. Este desierto inició su formación hace millones de años, ya que desde el Triásico se registran depósitos evaporíticos en la región, aunque las modernas condiciones de hiperaridez datan del Mioceno como resultado de la confluencia entre la zona subtropical de alta presión, la helada corriente de Humboldt a lo largo de la costa del Pacífico y los vientos marítimos que llegan al desierto (Clarke, 2006). La región está sujeta a tasas de erosión muy bajas y a la acumulación inusual de sales como percloruros, yoduros y nitratos en los suelos, así como halita, yeso y anhidrita (Nishiizumi et al., 2005; Ericksen, 1981, 1983; Bohlke et al., 1997).

A pesar de la extrema aridez del desierto de Atacama en el presente, existen evidencias que durante el Pleistoceno, e intermitentemente en el Holoceno, la región ha experimentado cierto grado de variabilidad climática. Desde hace algunos años varios investigadores (e.g., Grosjean et al., 1997; Latorre et al., 2006; Muñoz et al., 1997; Rech et al., 2002, 2003a, 2003b) han dirigido su atención al cambio climático en la zona. Por ejemplo, Grosjean et al. (1997) demostraron que entre 6200 y 3100 años antes del presente (a.P.) se registraron períodos de intensas lluvias en la región de la quebrada de Puripica cerca del salar de Atacama, al sur de Ramaditas.

Bajo estas condiciones es difícil explicar cómo las sociedades prehispánicas lograron asentarse y prosperar en un medio de tal hostilidad. De allí la importancia que atribuye Scarborough (2003) a la investigación sobre el manejo del agua, en especial porque es el recurso natural más preciado para la subsistencia y, como tal, elemento primordial susceptible de ser manipulado y controlado.

Aún más, podemos señalar que los procesos ecológicos en que las sociedades originarias que subsistieron en el marco del desierto de Atacama corresponden a transformaciones que toman largo tiempo en desarrollarse y ajustarse.

Debido a que tanto el acceso al agua como sus utilizaciones en la alimentación y protección o resguardo, consideradas estas necesidades básicas que han sido asumidas mediante reglas culturalmente prescritas, es que se hace necesario desarrollar un estudio antropológico multidisciplinario al respecto. Un estudio de esta naturaleza nos proporcionará los fundamentos para conocer e interpretar los orígenes sociales y las actividades de mantenimiento asociadas al desarrollo de los sistemas acuíferos y de qué forma estas impactaron la economía, organización política y relaciones de poder de las sociedades asentadas.

Aun más, el entendimiento de la relación aguahombre en el pasado tiene un gran significado actual, ya que nos proporcionará las bases para manejar eficientemente la protección de sistemas que, amén de ser hostiles, son tan frágiles.

Estudios previos realizados en diversas zonas del desierto de Atacama, y en especial en las áreas de Guatacondo y Tarapacá, demuestran que han sido dramáticamente más productivas en el pasado (Rivera, 1991, 2005). El hecho de que las sociedades hayan podido desarrollarse en estos ambientes y mantener niveles demográficos más altos que los actuales requieren de una explicación.

\section{Descripción del área arqueológica}

El sitio arqueológico de Ramaditas se localiza en el límite septentrional de uno de los ambientes más agrestes y extremos de América del Sur, el desierto de Atacama (Figura 1). A los 20 57' Latitud Sur y $69^{\circ} 21^{\prime}$ Longitud Oeste, en el valle de Guatacondo situado a $1.350 \mathrm{~m}$ de altura (Mostny, 1970: 271; Rivera, 1991) en la pampa del Tamarugal. El sitio concentra estructuras habitacionales y campos agrícolas de gran extensión que corresponden por ${ }^{14} \mathrm{C}$ al Período Cerámico Temprano (PCT) y a la fase Alto Ramírez entre 2600 y 2000 b.P. que se caracteriza por la evidencia más temprana de aldeas sedentarias asociadas con agricultura en la pampa, así como de 


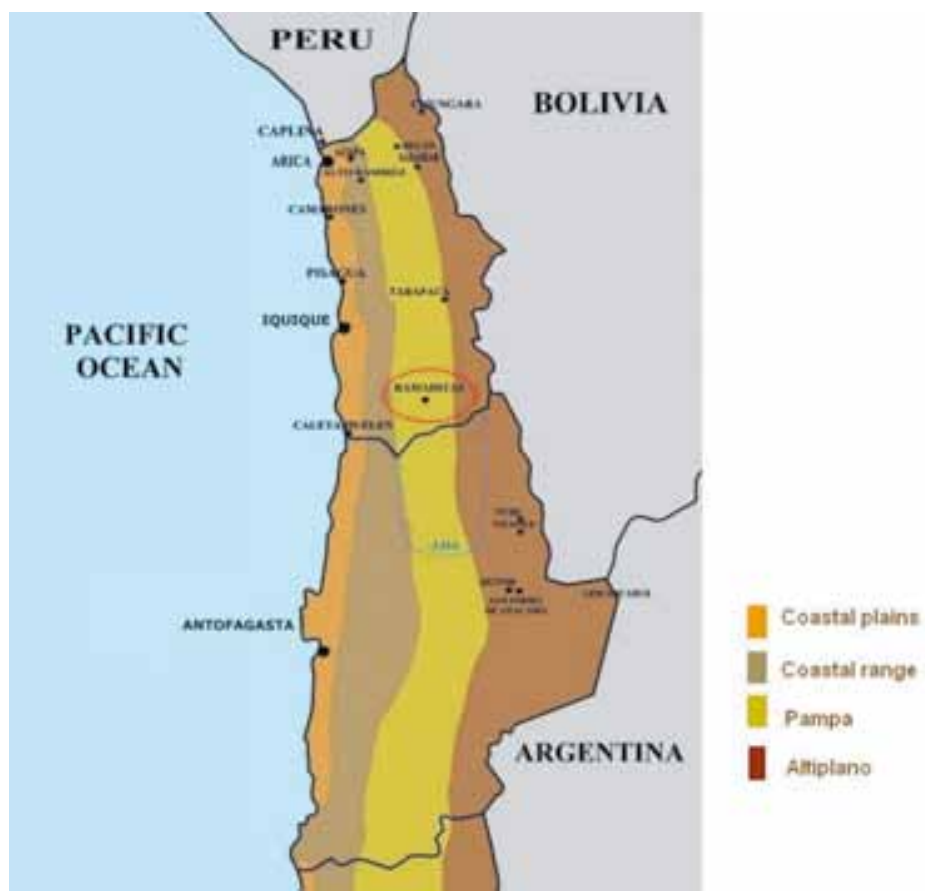

Figura 1. Mapa de localización del sitio arqueológico de Ramaditas, valle de Guatacondo.

intercambio de productos entre la costa y el altiplano (Rivera, 1991: 21, 2005: 9; Staller, 2005: 90).

La ocupación de Ramaditas contiene restos de superficie que se agrupan en cuatro conjuntos arquitectónicos, un montículo relativamente grande y varias estructuras domésticas rodeadas de campos de cultivos en donde se pueden distinguir al menos dos tipos de sistemas agrícolas:

1) Extensas áreas con eras o surcos sin limitación espacial y que aparentemente corresponden a un tipo de monocultivos menos intensivos $\mathrm{y}$,

2) Áreas que utilizan espacios cerrados pero interconectados que están bajo riego y que corresponderían al tipo de multicultivos más intensivos

El sistema de irrigación que se observa en Ramaditas puede ser considerado no solo como un fenómeno de adaptación al medio árido, también como una situación especialmente auspiciosa en que aún con muy poca agua puede haberse producido un suelo vegetacional insospechado sostenido por el medioambiente rico en nitrógeno. En Ramaditas, los campos de cultivos son mucho menos intensivos que la moderna agricultura del área. Incluye extensos surcos en zonas abiertas, en donde también se observan recintos más pequeños ocupando una extensión menor alimentados por canales subsidiarios. Este patrón agrícola relativamente extensivo no se ajusta con las características del medio ambiente actual y requiere de más análisis. El sistema de canales y surcos se adapta al contorno ondulado de la superficie del talud en una forma que hemos caracterizado como reticulado, o como una red dispuesta sobre la superficie.

Los restos macroflorales recuperados de estos surcos han sido identificados preliminarmente como variedades de Amaranthus, posiblemente cruentus o hypochondriacus, o, alternativamente, alguna variedad de Chenopodium.

Se obtuvo registros paleobotánicos de muestras de coprolitos de las excavaciones del Complejo 1 de Ramaditas y que son muy informativos respecto del polen, fitolitos, almidón, parásitos y residuos proteínicos.

Cheno-am domina el registro de polen, lo que sugiere un consumo en grandes cantidades tanto en su estado fresco como de semillas de miembros de este grupo de plantas emparentadas con la quínoa que es un Chenopodium. Cáscaras de Chenopodium son también mayoritarias en el registro de fitolitos $\mathrm{y}$, adicionalmente, Zea mays. En cuanto a gránulos de almidón, es importante Zea mays y en menor 
proporción Solanum tuberosum, lo que indica que también se consumió alguna forma de papa.

En total y, basado en los levantamientos topográficos y mediciones en terreno, calculamos una superficie de aproximadamente 600 hectáreas que han estado sometidas a cultivos con riego (Figuras 2 y 3 ).

Inmediatamente en torno a las estructuras habitacionales y los campos de cultivos se observan relictos de un antiguo bosque natural de Prosopis tamarugo, cuya materia prima ha sido utilizada como postes y vigas de soporte por los habitantes responsables de las estructuras habitacionales. Adicionalmente, de las habitaciones mismas se ha recuperado un centenar de postes.

\section{El medio ambiente holocénico y la quebrada de Guatacondo}

Con el inicio de la investigación arqueológica surgieron nuestras primeras incógnitas: ¿qué se cultivaba en estas circunstancias?, ¿cómo y de qué

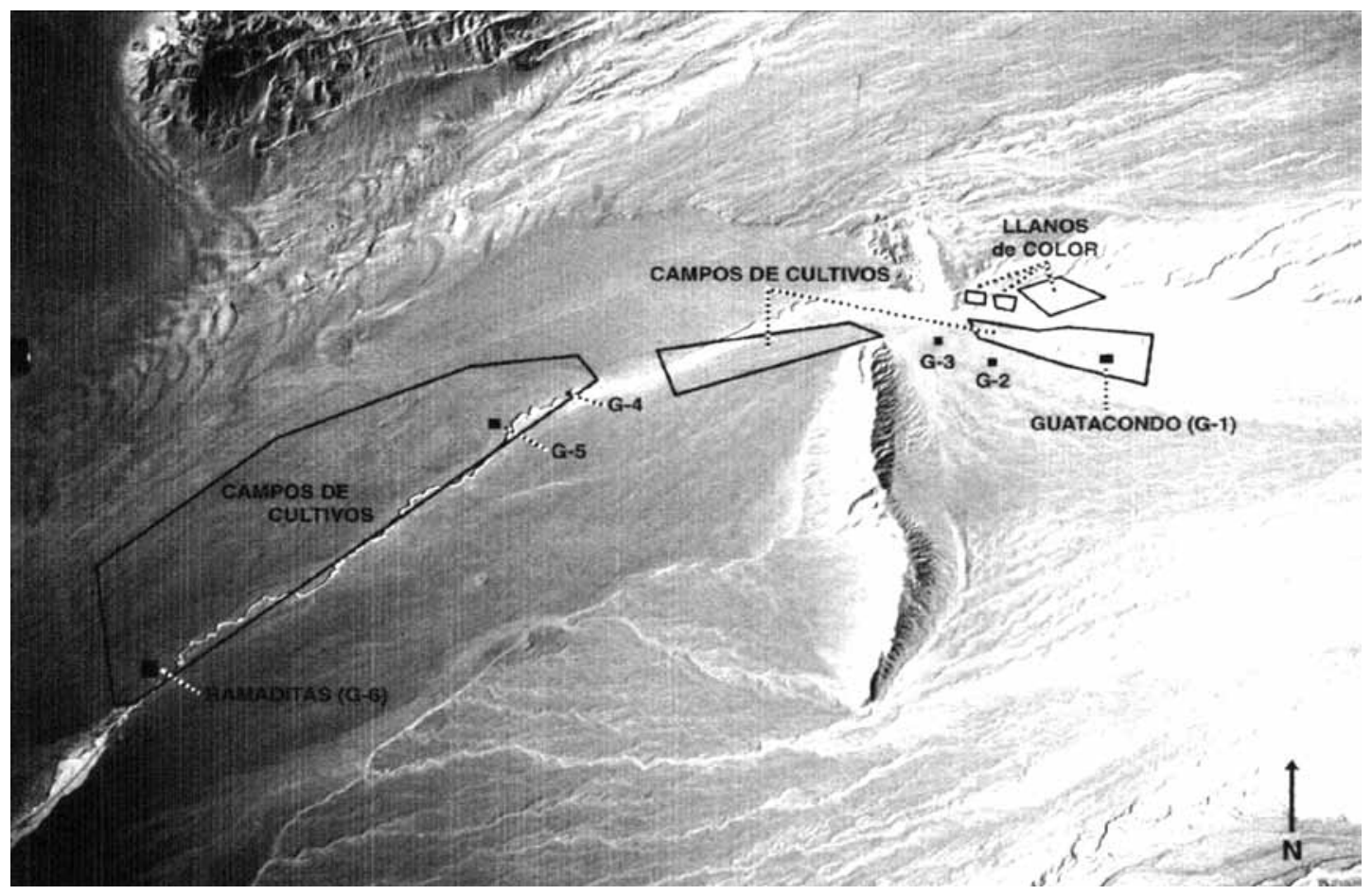

Figura 2. Vista aérea del sitio Ramaditas, Guatacondo, con indicación de campos de cultivos y sitios aledaños; escala 1: 50000, Fuente: Fuerza Aérea de Chile, Servicio Aerofotogramétrico, 1997.
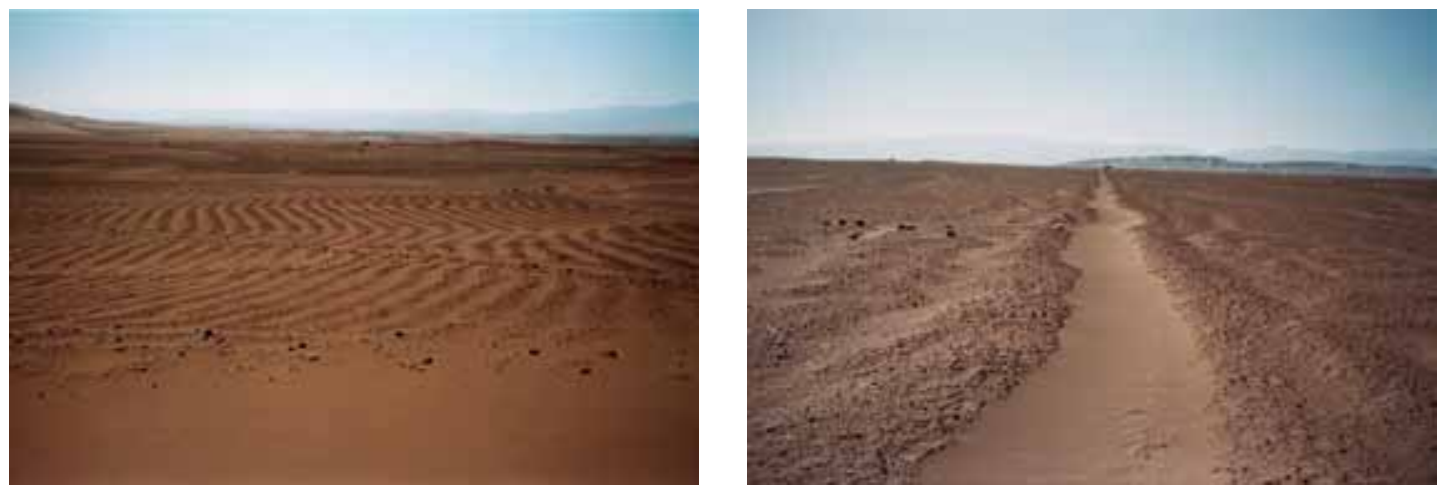

Figura 3. Surcos cultivados y canal principal de riego durante la ocupación Ramaditas $\sim 2600$ a.P. 
manera se lograban tales cultivos? Comprender la disponibilidad del recurso hídrico fue crucial en estas circunstancias y, en directa relación, la situación ambiental. En un panorama más amplio, incógnitas de espectro fundamental se constituyeron en nuestros objetivos mayores, a saber, ¿qué pudo haber causado la desaparición de las formaciones boscosas de Prosopis en Atacama? Si existió un cambio importante de las condiciones ambientales de la pampa del Tamarugal y por extensión al desierto de Atacama, ¿cuál pudo haber sido la causa de estos cambios?, y ¿cuál fue el impacto humano sobre el medio ambiente o viceversa?

A fin de responder estas cuestiones, dirigimos nuestra atención a la situación paleoambiental. Nuestros primeros intentos estuvieron dedicados a desarrollar modelos alternativos sobre la base de información paleoclimática del entorno del área centro-sur andina. Como resultado de esta primera aproximación, surgieron dos modelos que en parte se complementan, pero sobre la base de una interpretación diferente de las condiciones paleoclimáticas de la macrorregión.

Nuestra primera hipótesis fue que los campos cultivados de Ramaditas, fechados alrededor del 2600 a.P, no habrían dependido de la alimentación acuífera vía precipitaciones locales, puesto que estas han sido insignificantes durante el Holoceno tardío. La extensa red de canales con una estructura jerarquizada bastante compleja está conectada a las fuentes naturales de agua provenientes del escurrimiento de tierras altas más al Este. De tal forma que es importante llegar a comprender los patrones de cambios en precipitación en el Holoceno tardío especialmente en la cordillera andina o zona de puna para interpretar la secuencia y posibles causas de la ocupación y abandono de Ramaditas y otros sitios aldeanos de la región.

El modelo de Robert Bryson (2005: 53) hace referencia a otras propuestas paleoclimáticas de espectro macrofísico dependiendo de la información análoga capaz de desarrollar los algoritmos que se relacionan con distribuciones estacionales actuales de elementos climáticos particulares, tales como precipitación, temperatura o evapotranspiración potencial, a los movimientos estacionales de rasgos de mayor circulación. De allí que son importantes los registros de precipitación modernos de estaciones ubicadas en la cordillera próximas a los drenajes que se asocian al sitio de Ramaditas, especialmente para conocer el suministro de agua en época prehistórica. Evidencia de terreno indica que esta región del desierto, caracterizada por la hiperaridez, no ha recibido aportes significativos de precipitación local durante o después de la ocupación Ramaditas, y en donde el sistema de irrigación que ha mantenido los extensos campos de cultivos dependía exclusivamente de la alimentación que pudieran proveer las quebradas que aportan agua de las localidades altas ubicadas hacia la cordillera. Resultados preliminares de registros paleoclimáticos de estaciones vecinas ubicadas en la puna sugieren un nivel de precipitación suficiente y apropiado para mantener prácticas agrícolas en la pampa del Tamarugal, aunque siguiendo estos mismos registros también pudiera argumentarse un episodio de gran sequía como causante del abandono de la región.

Siguiendo a Bryson en sus observaciones respecto de los trabajos arqueológicos de terreno en Ramaditas advierte que, por ejemplo, la remoción de grandes cantidades de arena de depositación eólica a través de intensas excavaciones ha revelado que los rasgos arquitectónicos de piedra y barro y los pisos de ocupación están muy bien conservados. Los muros de los complejos no fueron diseñados para resistir precipitaciones significativas, y aunque son relativamente poco estables por varias otras razones, ellos no muestran signos de erosión a causa de las lluvias. Tampoco los pisos ocupacionales excavados hasta el momento parecen haber sido afectados. Las investigaciones preliminares sugieren que este puede haber sido el caso a lo largo de todo el drenaje de Guatacondo. Una sola excepción a esta aseveración la constituye el hecho de que algunas estructuras del Complejo 4 de Ramaditas (sitio G-6 en la serie regional) y también del sitio aldea G-4 ubicado aguas arriba, han sido afectados por corrientes canalizadas en forma de meandros, en el primer caso, y por incisiones profundas en la quebrada actual, en el último de los casos (Bryson 2005: 43,44). Tests de prueba han revelado que la estratigrafía de los surcos de los campos de cultivos se presenta todavía en gran medida intacta, a pesar de los cambios en su orientación dispuestos para acomodar los flujos hidráulicos cambiantes (Ramírez de Bryson et al., 2001). De acuerdo con Bryson, se puede asegurar entonces que los mismos procesos fluviales que han afectado porciones de los complejos residenciales también han modificado o destruido secciones del sistema agrícola. Sin embargo, estas observaciones sugieren que las precipitaciones locales durante o 
después de la ocupación han sido muy limitadas y que los primeros habitantes del área deben haber recurrido al agua, producto de las avenidas desde las tierras más altas, para desarrollar su agricultura. En consecuencia, el régimen de lluvias del pasado en la cordillera occidental inmediatamente al Este de la quebrada de Guatacondo es de gran interés.

Los extensos campos de cultivos de la cuenca de Guatacondo están condicionados por la inclinación natural del 3,5\% de la topografía local, para permitir el movimiento del agua para riego desde los drenajes naturales hacia las unidades de riego de regulares dimensiones. Los canales de irrigación son más bien pequeños y bajos y utilizan unas compuertas relativamente pequeñas, consistiendo de dos piedras verticales a cada lado y una transversal, para distribuir agua y controlar su flujo hacia los surcos. Además, los canales naturales que alimentan el sistema de canales son también poco profundos y extensas áreas de la pendiente lavada es todavía visible aguas abajo de Ramaditas, indicando una napa más alta que aquella sugerida por la actual quebrada profunda y angosta, misma que con seguridad también alimentó los bosques naturales de Prosopis que rodean el sitio de Ramaditas. De allí que las avenidas de agua que alimentan el sistema fueran casi con seguridad bastante consistentes, aunque de una baja intensidad. Aún más, tanto los restos de maíz como de Amaranthus encontrados en Ramaditas en contextos arqueológicos requiere, para ser viable, de un período de crecimiento más largo de lo que es posible en las condiciones actuales considerando la disponibilidad de agua estacional. Estos factores según Bryson indican que debió haber una temporada lluviosa prolongada en el verano de la cordillera, en forma continua, con avenidas de baja intensidad a lo largo de la quebrada de Guatacondo en el momento en que el sistema de irrigación se encontraba funcionando.

Para Bryson las tendencias que emergen de este $\mathrm{y}$ otros modelos similares de estaciones en la puna de más al norte parecen bastante de acuerdo con las interpretaciones de registros paleoambientales provenientes de otros lugares de los Andes centro-sur y con los resultados de los Modelos de Circulación General ya conocidos en la literatura. A juicio de Bryson: These patterns indicate that the extreme aridity $\mathrm{pf}$ the mid-Holocene ended in this region at about $3500^{14} \mathrm{C}$ yr B.P "and that during the occupation of Ramaditas precipitation was relatively high while maximum precipitation intensity was at a Holocene low. If it can be assumed that the models understate the degree of variability in precipitation and, indeed, that the model for Uyuni is representative of higher elevations to its west, then it would appear that the major drought centered at ca. 2000-1800 ${ }^{14} \mathrm{C} \mathrm{yr}$ B.P. and the concomitant increase in precipitation intensity seen in the models would account for the abandonment of the Guatacondo drainage near that time (Bryson, 2005: 61) (Figuras 4 y 5).

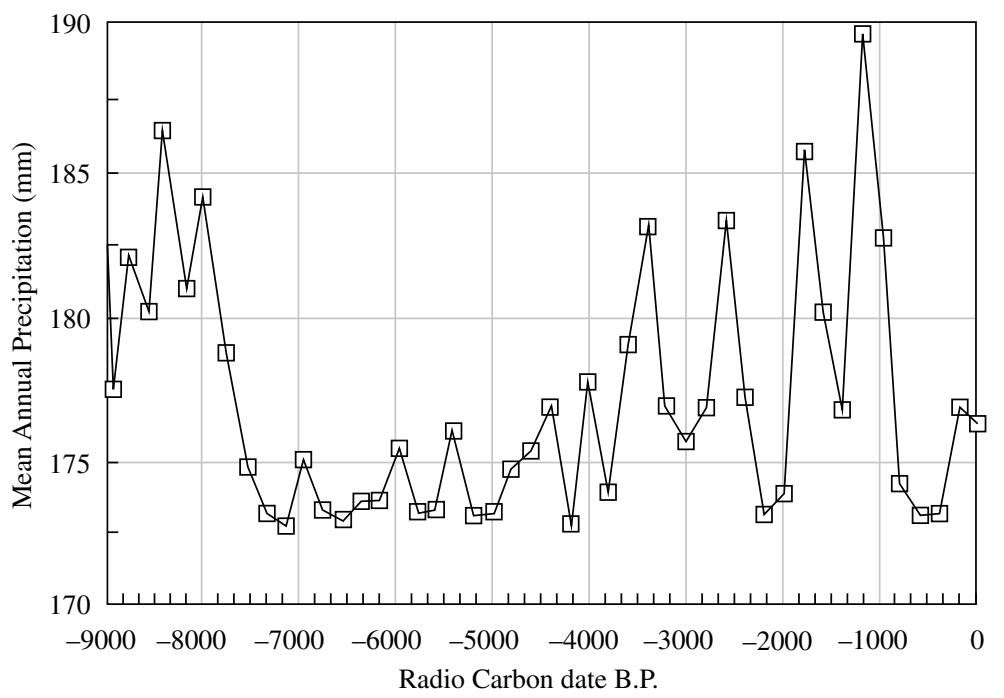

Figura 4. Índices de precipitación de Uyuni, Bolivia, ${ }^{14} \mathrm{C} 9000$ años a.P., modelada con intervalos representando 200 años de promedio anual en mm (de acuerdo con Bryson 2005: 56). 


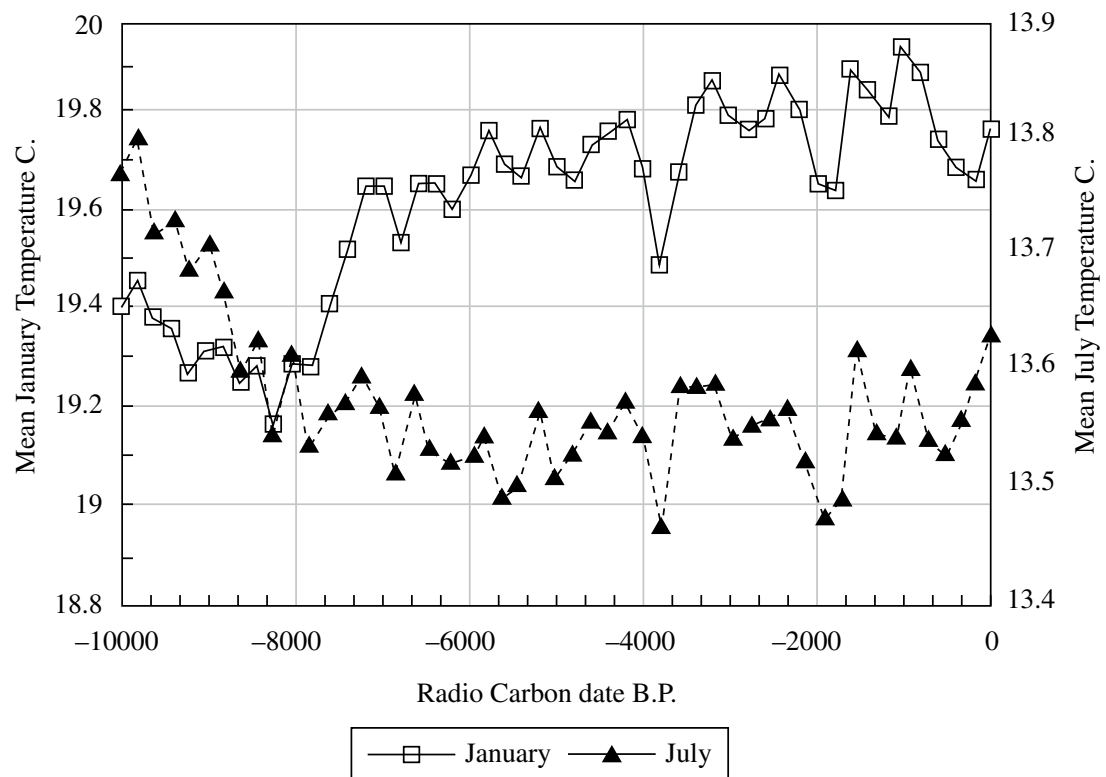

Figura 5. Historia modelada de la temperatura del Holoceno en colonia Pintado. Símbolos cuadrados aplicables a la temperatura promedio de enero pueden ser leídos en la escala a la izquierda. Promedios de temperatura de julio (triángulos) corresponden en la escala a la derecha. Puntos individuales representan valores promedio mensuales cada 200 años de intervalo (de acuerdo con Bryson, 2005: 58).

Por otro lado, Carlos Baied ha enfatizado un modelo complementario que sugiere, sobre la base de datos paleoecológicos obtenidos de sitios como laguna seca, El Aguilar y Sajama, en la puna seca al norte de los $23^{\circ} \mathrm{S}$, indicarían "condiciones potencialmente aptas para el establecimiento de poblaciones permanentes, si bien como resultado de procesos sensiblemente opuestos" (Baied, 2005: 69).

El modelo de Bryson interpreta las condiciones ambientales de Ramaditas como parte de un panfenómeno que ha caracterizado gran parte de la macroárea andina centro-sur, aunque cauciona que se deben obtener más y mejores datos climáticos especialmente de la región desértica. Baied, por su parte, entrega una visión más acotada a regiones específicas dentro del espectro andino centro-sur. Es concluyente cuando contrasta la situación del llamado "silencio arqueológico" en la región árida con el área de más al norte en el sitio de Asana en Perú o la zona de Antofagasta de la sierra en el Nor Oeste de Argentina, siendo taxativo en el sentido de considerar microrregiones con diferentes comportamientos climáticos.

Ante esta dicotomía, y dispuestos a desarrollar una nueva metodología para recabar mayor información paleoclimática especialmente del área desértica, enfocamos nuestra investigación a los análisis dentrocronológicos. Para ello encauzamos nuestra atención en el uso de vigas y postes de madera del género Prosopis que fueron utilizados en la construcción de los recintos habitacionales de Ramaditas, más la disponibilidad de árboles vivos en el área y de material enterrado producto de las inundaciones a causa de las precipitaciones en la meseta altoandina. Esto nos ha permitido colectar suficientes muestras para dar pasos preliminares en la realización de las primeras cronologías que posteriormente nos han permitido desarrollar análisis más específicos para tentativamente lograr reconstrucciones paleoclimáticas del desierto de Atacama.

Inicialmente el estudio dendrocronológico pretendía lograr las primeras cronologías de material tanto arqueológico como vivo, a fin de comprender la dinámica del ciclo hídrico y del manejo del desierto por parte de sociedades que lograron producir en una de las áreas más inhóspitas del planeta hace más de 2600 años. De esta forma, como los primeros análisis fueron exitosos, nos propusimos investigar sobre la posibilidad de ubicar material más antiguo a través de prospecciones en ámbitos freáticos relictuales en la gran cuenca de Llamara. Con el descubrimiento de bosques de tamarugos 
de más de 8000 años de antigüedad fue posible aplicar análisis más sofisticados, que consisten en lograr información sobre valores de isótopos de oxígeno contenidos en celulosa- $\mathrm{d}^{18} \mathrm{O}$ de las anillas de Prosopis tamarugo.

En consecuencia, los resultados del proyecto de investigación que aquí se presentan están orientados a entregar información sobre la historia de las condiciones climáticas y medioambientales del desierto de Atacama que a su vez se complementan con las secuencias obtenidas a partir de Polylepis tarapacana (queñua) en las tierras altas vecinas, cuyas series presentan una cronología retrospectiva de hasta 800 años (Argollo, 2004; Soliz et al., 2009; Christie et al., 2009; Moya, 2006).

\section{Medio ambiente y arqueología}

Fisionómicamente la pampa del Tamarugal es una gran cuenca endorreica que en la actualidad se encuentra completamente seca y cubierta en las partes más bajas con una gruesa capa de sales. Esta cuenca se encuentra rodeada en la parte oriental por grandes abanicos aluviales formados a la salida de las quebradas que abandonan la cordillera de los Andes formando depósitos pedemontanos. En la parte occidental, la pampa se ve limitada por la cordillera de la Costa. Se extiende desde $19^{\circ} 17^{\prime} \mathrm{S}$ hasta los $21^{\circ} 20^{\prime} \mathrm{S}$ de latitud Sur.

Según Di Castri y Hajek (1976), climatológicamente esta área corresponde al desierto absoluto. Gajardo (1993) clasifica el área como subrregión del desierto del Tamarugal debido a la influencia de las napas freáticas que sustentan la presencia de vegetación mayor. Las temperaturas se caracterizan por presentar marcadas oscilaciones diarias, fluctuando entre mínimas absolutas de $-5 \mathrm{a}-12^{\circ}$ C y con máximas absolutas de 36 y $40^{\circ} \mathrm{C}$, con un promedio de 250 días despejados al año.

La humedad relativa del aire registrada muestra grandes oscilaciones diarias, especialmente en los meses de septiembre a marzo, alcanzando 3-10\% durante el día y 80-100\% en la noche, manteniéndose durante 4 a 5 horas, para luego caer abruptamente a mediodía (Fuenzalida, 1971).

Respecto de los suelos, el sector oriental y a la vez más alto de la pampa corresponde a un gran piedemonte con estratificación grosera, no estructurado, con alto contenido salino y carente de materia orgánica. Los sectores más bajos corresponden a la sección occidental formada por suelos estratificados, con materiales más finos y cubiertos con una costra salina que va desde unos pocos centímetros hasta un metro o más de profundidad. En estos suelos predominan los materiales arcillosos y limosos, estratificados y con una cubierta de sales de espesor variable que va de unos pocos centímetros hasta un metro o más. Las sales que componen estos salares son, generalmente, de sodio, calcio, magnesio y potasio, delicuescentes, de modo que da la impresión de encontrar un suelo permanentemente húmedo. (IREN, 1976).

En estas condiciones es que se desarrolla el tamarugo (Prosopis tamarugo Phil.), árbol que pertenece al orden Leguminosas, familia de las Mimosáceas (Figura 6). Es una especie endémica

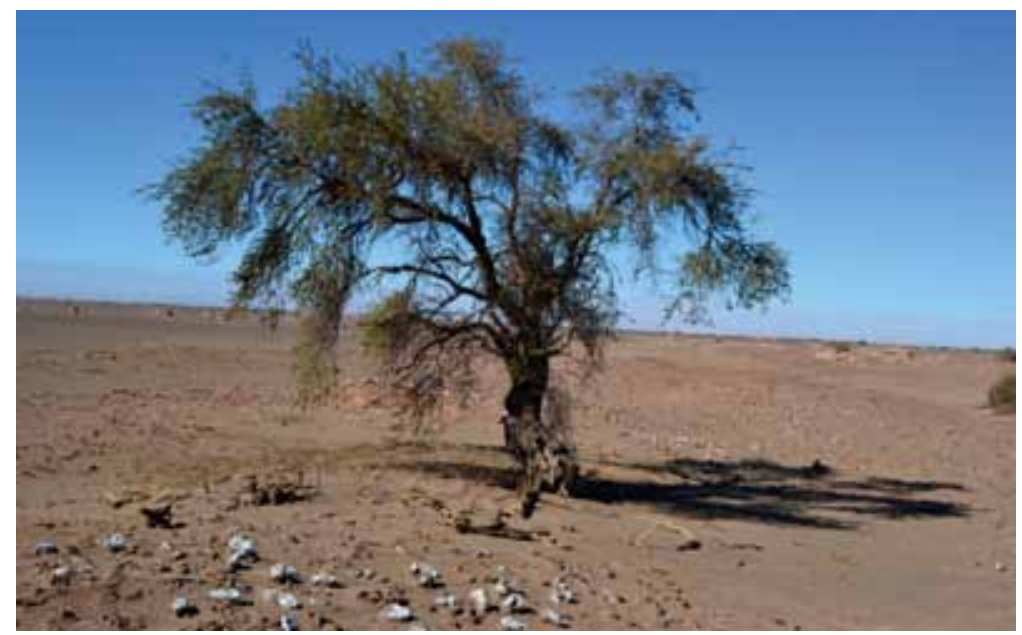

Figura 6. Ejemplar de Prosopis tamarugo Phil. moderno en la pampa del Tamarugal, desierto de Atacama. 
de un área específica del desierto de Atacama que a pesar de su gran importancia ecológica es poco conocida, ignorándose las etapas de desarrollo desde su aparición.

Estudios previos han determinado edades aproximadas a los cuatrocientos años, creciendo sobre los salares de la pampa del Tamarugal con ausencia casi total de precipitaciones, aprovechando solamente las aguas subterráneas. Además, recientes fechados de restos de Prosopis ubicados en relictos de bosques que extienden la presencia de esta especie por más de 7000 años. Como bien indican Beresford-Jones et al. (2009: 309): as witnesses of ecological change, Prosopis fossils effectively "compress time".

El tamarugo posee un sistema radicular doble, conformado por una raíz pivotante o de anclaje, formado por tres a cuatro raíces gruesas, suberizadas y lignificadas que alcanzan una profundidad máxima en suelos francos de 7 a 8 metros (Sudzuki, 1969), y una masa o conjunto de raíces absorbentes laterales 20 a 50 centímetros de espesor, que abarca un perímetro aproximadamente igual a la copa del árbol (Ffolliott y Thames, 1983).

La fisiología del tamarugo es muy particular, en determinadas condiciones de alta humedad atmosférica (sobre $80 \%$ ), absorbe agua a través de su sistema foliar transportándola al sistema radicular y depositándola en la microrrizósfera de donde es reabsorbida como agua (Sudzuki, 1969).

Inicialmente desarrollamos análisis experimentales dendrocronológicos utilizando muestras históricas y prehistóricas de Prosopis tamarugo. Sus principales resultados han sido publicados y expuestos en anteriores reuniones (Rivera et al., 2010), de manera que solo nos abocaremos a dejar establecido las principales conclusiones del mismo.

Resumidamente, se obtuvo dos cronologías de ancho de anillos. La primera secuencia a partir de las muestras arqueológicas de la aldea Ramaditas. La segunda cronología se logró de muestras de diferentes localidades de la pampa del Tamarugal.

La cronología generada en Ramaditas abarcó un total de 90 años. En tanto, la longitud de la cronología de muestras actuales de tamarugo y algarrobo alcanzó 76 años (Tabla 1).

Los resultados preliminares que se obtuvieron de los análisis dendrocronológicos confirmaron la factibilidad de la metodología utilizada. Así, la sensibilidad media de la cronología Ramaditas con valores de 0,342 representado a partir de los estadígrafos de pampa Tamarugal (La Tirana) y Ramaditas resulta indicativa.

La Tabla 2 muestra la desviación estándar para ambas cronologías: de 0,437 para Ramaditas y de 0,278 para pampa del Tamarugal. La autocorrelación de primer orden también resultó ser similar en ambos sitios con valores superiores a $0,4(0,489$ y 0,6958 para Ramaditas y pampa del Tamarugal, respectivamente). En la misma Tabla se destaca la similitud en ambos sitios para los valores de la varianza del primer autovector y de la correlación entre árboles.

En la Figura 7 se observa el valor medio de las mediciones crudas de todas las muestras incluidas en la cronología maestra de Ramaditas, ajustadas a una curva exponencial negativa, donde destacan los altos y bajos en el crecimiento de los anillos. Esta situación indica claramente la potencialidad de

Tabla 1. Resumen de series incluidas en las cronologías (Rivera et al., 2010)

\begin{tabular}{|c|c|c|c|c|}
\hline Sitio & $\begin{array}{c}\mathrm{N}^{\circ} \text { total series } \\
\text { medidas }\end{array}$ & $\begin{array}{l}\mathrm{N}^{\mathrm{o}} \text { series incluidas } \\
\text { en cronología final }\end{array}$ & $\begin{array}{l}\text { Amplitud } \\
\text { Inicio Final }\end{array}$ & Años \\
\hline Ramaditas & 51 & 40 & 90 & 90 \\
\hline Pampa del Tamarugal & 42 & 23 & 1932 & 76 \\
\hline
\end{tabular}

Tabla 2. Resumen de los estadígrafos arrojados por el programa ARSTAN para las cronologías Ramaditas y pampa del Tamarugal (estadígrafos cronologías estándar). (Rivera et al., 2010)

\begin{tabular}{lccccc}
\hline \multicolumn{1}{c}{ Sitio } & $\begin{array}{c}\text { Sensibilidad } \\
\text { media }\end{array}$ & $\begin{array}{c}\text { Desviación } \\
\text { estándar }\end{array}$ & $\begin{array}{c}\text { Autocorrelación } \\
\text { de 1 } 1^{\text {er }} \text { orden }\end{array}$ & $\begin{array}{c}\text { Varianza del } \\
1^{\text {er }} \text { autovector }\end{array}$ & $\begin{array}{c}\text { Correlación } \\
\text { entre árboles }\end{array}$ \\
\hline Ramaditas & 0,3420 & 0,437 & 0,4892 & $30,3 \%$ & 0,280 \\
Pampa del Tamarugal & 0,1898 & 0,278 & 0,6958 & $50,7 \%$ & 0,152 \\
\hline
\end{tabular}




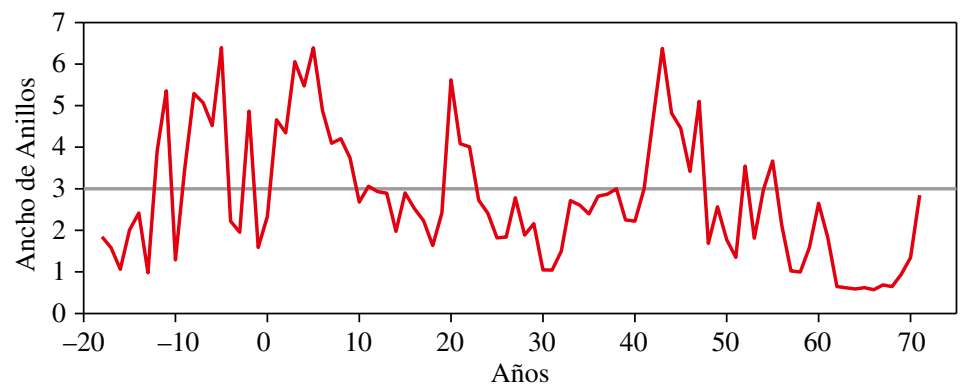

Figura 7. Valor medio del total de las mediciones para las muestras colectadas en el sitio arqueológico Ramaditas (Rivera et al 2010).

las muestras del sitio arqueológico de Ramaditas, debido a que presentan variaciones muy claras en el crecimiento de los anillos entre un año y otro. Esta situación se debe a la respuesta de los árboles a las variaciones del clima imperante en la zona, mostrando períodos de mayor incremento del ancho de los anillos en respuesta a mejores condiciones para el crecimiento.

En los últimos años se ha establecido con mayor certeza el fenómeno que la estacionalidad es un componente crítico de las variaciones climáticas, por tanto, para mejorar los modelos de predicción sobre la variabilidad climática del futuro es necesario conocer las variaciones subanuales de los registros paleoclimáticos. El estudio de las anillas de los árboles ha sido utilizado por mucho tiempo para describir los cambios en las variables climáticas, como temperatura y precipitación, sin embargo, los anchos de las anillas por sí solo muchas veces están limitados en relación con cuantificar las variaciones subanuales. De allí que estudios recientes han demostrado que las variaciones de las proporciones de isótopos de oxígeno ${ }^{16} \mathrm{O}$ y ${ }^{18} \mathrm{O}$ (típicamente conocidas como valores ${ }^{18} \mathrm{O}$ en \%o) son herramientas poderosas en la interpretación de las variaciones subanuales de precipitación (Dodd et al., 2008). La composición de celulosa- $\delta^{18} \mathrm{O}$ en el isótopo de oxígeno y que es un componente principal en la célula de las plantas se forma secuencialmente en las anillas de los árboles y a menudo se encuentra bien correlacionado con valores de precipitación del isótopo de oxígeno. Como la madera se conserva por mucho tiempo, especialmente en ambientes áridos como el desierto de Atacama, los valores isotópicos de oxígeno en celulosa- $\delta^{18} \mathrm{O}$ de las anillas pueden entregar registros de variabilidad de precipitación en escalas de tiempo muchísimo más grandes que los registros meteorológicos históricos. De esta manera, nuestro primordial objetivo es desarrollar conjuntos de registros sobre variabilidad de precipitación y/o recursos hídricos a partir de valores de isótopos de oxígeno en celulosa- $\mathrm{d}^{18} \mathrm{O}$ de anillas de árboles, en este caso de Prosopis tamarugo del desierto de Atacama.

Con el objetivo de obtener una mejor documentación acerca de la problemática paleoclimática de la zona hemos iniciado una investigación complementaria basada en la resistencia de Prosopis tamarugo

Tabla 3. Fechados radiocarbónicos de Prosopis (AMS)

\begin{tabular}{llll}
\hline Muestra & \multicolumn{1}{c}{ Ubicación } & Calibrated yrs. BP & UTM (WGS 84) \\
\hline LTR-01 & La Tirana Refresco & na - moderno & $19 \mathrm{~K} 431478,7751186$ \\
RAM12-13 & Ramaditas & $2030 \pm 40$ & $19 \mathrm{~K} 461899,7675455$ \\
RAM-131 & Ramaditas & $2615 \pm 135$ & $19 \mathrm{~K} 461819,7675315$ \\
RAM12-10 & Ramaditas & $2660 \pm 40$ & $19 \mathrm{~K} 461819,7675315$ \\
LL12-15 & Llamara Basin & $4775 \pm 7 / 4500 \pm 113$ & $19 \mathrm{~K} 436000,7648209$ \\
LL-680b & Llamara Basin & $7910 \pm 10 / 7870 \pm 10$ & $19 \mathrm{~K} 434009,7661014$ \\
LL12-03 & Llamara Basin & $7910 \pm 99$ & $19 \mathrm{~K} 431429,7654466$ \\
LL12-05 & Llamara Basin & $8370 \pm 57$ & $19 \mathrm{~K} 431641,7654360$ \\
LL12-04 & Llamara Basin & $9070 \pm 28 / 9005 \pm 35$ & $19 \mathrm{~K} 431600,7654360$ \\
LL-778 & Llamara Basin & $9130 \pm 145$ & $19 \mathrm{~K} 435466,7648515$ \\
\hline
\end{tabular}


a las sequías, fenómeno que podría darnos buenas claves para conocer las fluctuaciones de humedad en la región en los últimos 10000 años. Para ello, con la colaboración del geoquímico Dr. Justin Dodd (Northern Illinois University), hemos iniciado un proyecto que incluye análisis de isótopos de oxígeno de fragmentos de Prosopis tamarugo con la finalidad de registrar variaciones subestacionales de disponibilidad de humedad y fuentes hídricas en muestras de los sitios de La Tirana (moderno), Ramaditas (2615 Cal BP) y Llamara (9130 y 7920/7860 Cal BP) (Tabla 4). La información que estamos logrando es crítica, en cuanto nos permite conocer cómo la disponibilidad de agua y su uso y manejo en la pampa del Tamarugal ha afectado el desarrollo de aspectos fundamentales de las ocupaciones humanas en el área.

Resultados preliminares obtenidos a partir del análisis isotópico de oxígeno de anillas de tamarugos indican que la región ha estado sometida a un sostenido incremento de la aridez en los últimos 10000 años, probablemente como resultado del decrecimiento del volumen de agua desde sus áreas

Tabla 4. Datos Preliminares de Isótopo de Oxigeno (Rivera et al. 2012)

\begin{tabular}{lccc}
\hline Muestra & $\begin{array}{c}\text { \# muestra } \\
\text { (anillas) }\end{array}$ & $\delta^{18} \mathrm{O}$ & $\begin{array}{c}\text { intra-ring } \\
\text { variabilidad } \\
\text { promedio }\end{array}$ \\
\hline LTR-01 & $38(9)$ & 33,1 a $36,3 \% \circ$ & $1,5 \% \circ$ \\
RAM-131 & $29(7)$ & 17,5 a $35,6 \% \circ$ & $4,5 \% \circ$ \\
LL-680b & $10(6)$ & 23,8 a $32,8 \% \circ$ & $3,0 \% \circ$ \\
\hline
\end{tabular}

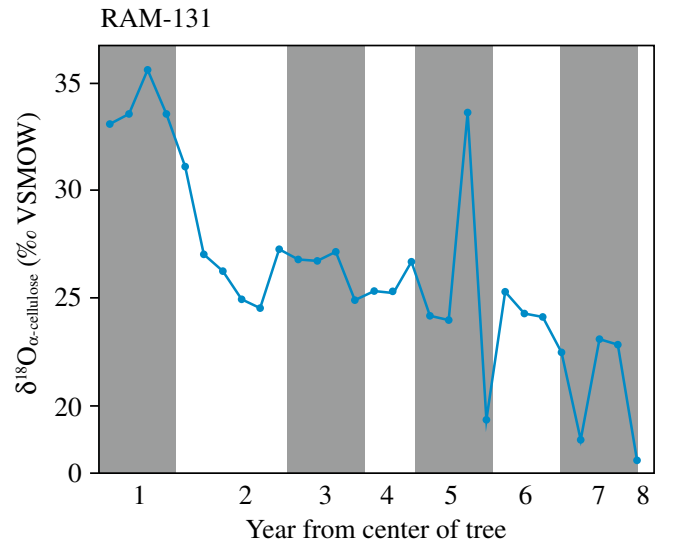

de recarga. Los valores de isótopos de oxígeno de la celulosa- $\delta$ de las anillas de $P$. tamarugo de la cuenca de Llamara $(9130 \pm 145$ y 7910 a $7870 \pm$ 10 Cal BP), Ramaditas ( $2615 \pm 135$ Cal BP) y La Tirana Refresco (moderno) registran variaciones subanuales en la disponibilidad de agua subterránea en la pampa del Tamarugal. Valores bajos de $\delta^{18} \mathrm{O}$ $(23,8$ a $32,8 \%$ o $)$ en las muestras de $P$. tamarugo de la cuenca de Llamara indican condiciones más húmedas ( $~ 9 \mathrm{ka}$ ), sin embargo, la variabilidad subanual de los valores de $\delta^{18} \mathrm{O}$ permanece relativamente alta, con un promedio en los valores intraanillas de $3,0 \%$ o $(2 \sigma=1,1 \% o)$ (Figura 8).

Los postes de $P$. tamarugo que fueron utilizados como soporte de techumbres y que provenían del bosque circundante al sitio arqueológico de Ramaditas tienen valores más amplios $\delta^{18} \mathrm{O}(17,5$ a $35,6 \%$ ) y una variabilidad intraanillas más grande (promedio 4,5\%o, $2 \sigma=3,2 \%$ ). El mayor rango interanual y subanual de valores $\delta^{18} \mathrm{O}$ refleja probablemente un período con flujos muy variables de la disponibilidad hídrica en la forma de escurrimiento superficial o recarga subterránea (Figura 8). De la muestra RAM-131, que corresponde a un fragmento del tronco, se pudo identificar 7 anillas con valores $\delta^{18} \mathrm{O}$ que van de $17,5 \%$ a $35,6 \%$, con una variabilidad intraanillas promedio de $4,5 \%$ (Dodd y Rivera, 2012). El abandono de Ramaditas y de otros sitios contemporáneos parece coincidir con los cambios en la disponibilidad de agua en la región. Muestras modernas de $P$. tamarugo del área de La Tirana-Refresco recolectadas en 2008 tienen valores $\delta^{18} \mathrm{O}$ que son consistentemente más altos $(33,1$ a $36,3 \%$ o $)$ con una variabilidad intraanillas

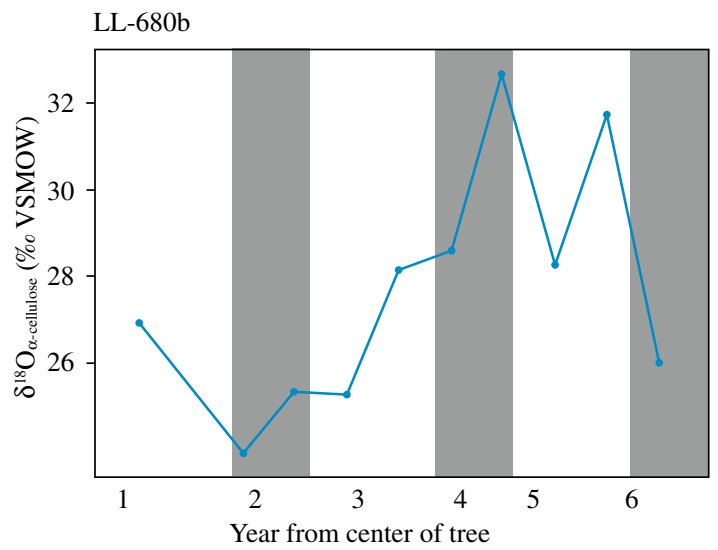

Figura 8. Muestras RAM-131 y LL-680b, se observan períodos más húmedos insertos en períodos de extrema aridez en el área del Desierto de Atacama (Rivera et al. 2012). 
mucho más baja $(1,5 \%, 2 \sigma=0,9 \%$ ) , que indicaría condiciones persistentemente más áridas y mayor efecto evaporativo en el agua que alimentaba los árboles de P. tamarugo (Figura 9).

Hoy la cuenca de la pampa del Tamarugal tiene un sistema multiacuífero que esá asociado con áreas de recargas a diferentes alturas en el Altiplano (e.g. Aravena, 2005; Aravena y Suzuki, 1990; Aravena

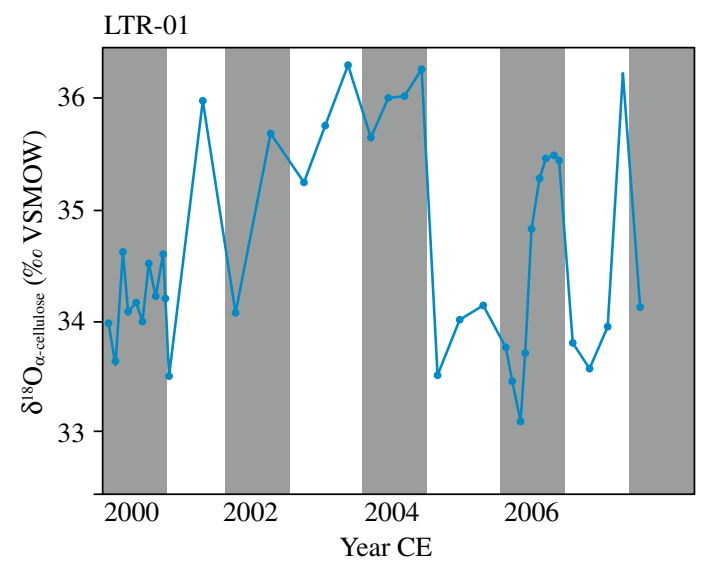

Figura 9. Muestra LTR-01 moderna de Prosopis, se observa variabilidad inter e intra anillas con bajos valores $\delta^{18} \mathrm{O}$ (Rivera et al. 2012). et al., 1999). Evaporación extrema en aguas superficiales de la pampa del Tamarugal resultan en valores $\delta^{18} \mathrm{O}$ altos. Aguas subterráneas de la pampa del Tamarugal es una mezcla de precipitaciones en áreas más altas de la cordillera (LMWL) y aguas que provienen de evaporación en las zonas no saturadas de recarga (Figura 10).

\section{Conclusiones}

En América del Sur, y más específicamente el desierto de Atacama, las especies de los géneros Prosopis, Ephedra y Polylepis constituyen los únicos ejemplares leñosos con posibilidades ciertas en futuros estudios dendroecológicos. (Boninsegna, 1992; Morales et al., 2001, 2004; Argollo et al., 2004; Moya, 2006; Christie et al., 2009). Las rigurosas condiciones del medio ambiente donde crece Prosopis tamarugo permiten que la variabilidad interanual se vea reflejada en el crecimiento de los anillos de los árboles, haciendo de la pampa del Tamarugal una fuente importante de registros dendrocronológicos y dendroarqueológicos.

La calidad de los estadígrafos obtenidos en las dos cronologías desarrolladas, Ramaditas y pampa del Tamarugal, indica claramente que las cronologías

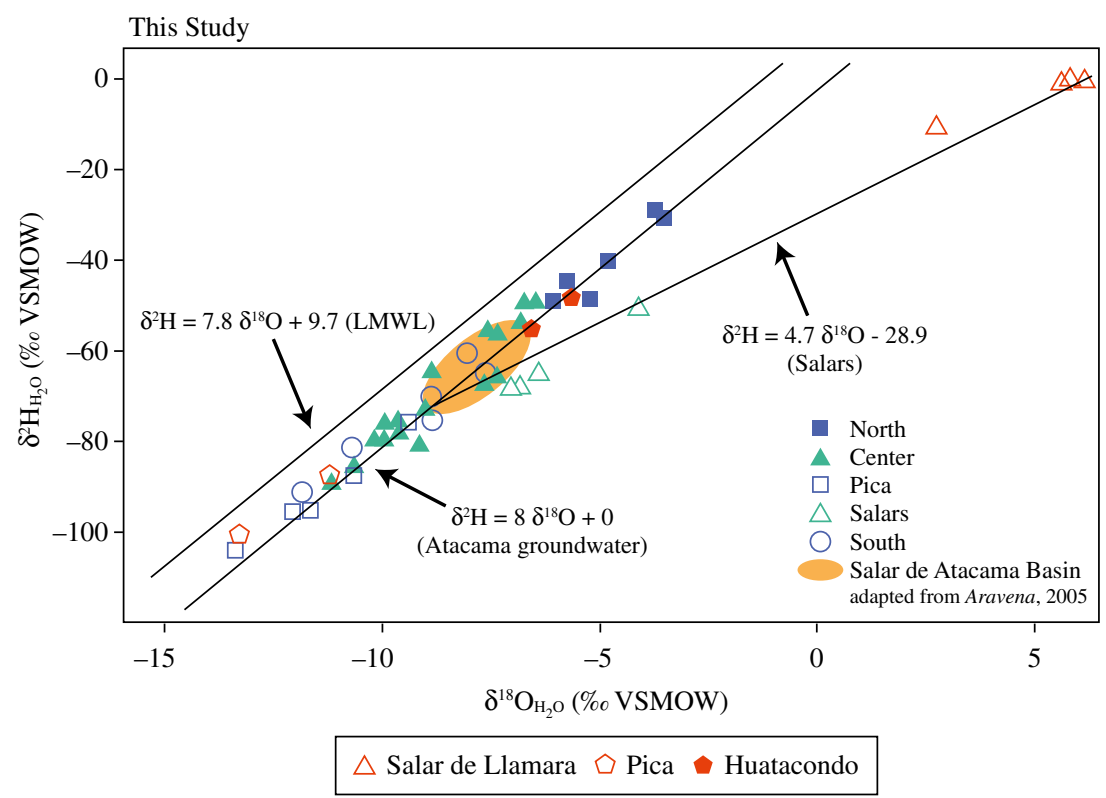

Figura 10. Variaciones isotópicas de agua superficial y subterránea (adaptado de Aravena, 2005) Agua subterránea en la pampa del Tamarugal valores $\delta^{18} \mathrm{O}-13,4$ y $-3,8 \%$ (Aravena, 2005) Ríos y arroyos del Norte de Chile valores $\delta^{18} \mathrm{O}-14,0 \mathrm{a}-6,2 \%$ (Aravena y Suzuki, 1990) Agua superficial: salar de Llamara, pampa del Tamarugal valores $\delta^{18} \mathrm{O}+2,8 \mathrm{a}+6,1 \%$ (Dodd y Rivera, 2012) 
de P. tamarugo y P. alba, tanto en su versión arqueológica como contemporáneas, son adecuadas para ser utilizadas en futuras reconstrucciones climáticas y ambientales del pasado. Los estadígrafos Rbar y EPS indican que hay una señal común adecuada, a excepción de un pick en la cronología Ramaditas y dos en la cronología pampa del Tamarugal. La disminución de la relación se debe al bajo número de muestras que alcanzaron a ser cofechadas, como también al bajo número de muestras colectadas, lo cual no afecta la calidad final de las cronologías.

Con los resultados obtenidos hasta el momento se puede decir categóricamente que las muestras de tamarugo cofechan entre ellas y pueden ser utilizadas para futuras reconstrucciones climáticas. Por otro lado, resultados preliminares de valores de isótopo de oxígeno en la celulosa- $\delta$ de las anillas de tamarugo aplicada con el fin de obtener información sobre precipitación y variabilidad de fuentes de agua registran variaciones interanuales y estacionales significativas. Es probable que las condiciones actuales extremadamente áridas del desierto de Atacama hayan tenido un comportamiento medioambiental totalmente distinto en el pasado. Variaciones interanuales y estacionales en los valores $\delta^{18} \mathrm{O}$ son significativas tanto en aguas subterráneas como de superficie en la pampa del Tamarugal en los últimos 10000 años. En condiciones tan excepcionales, la disponibilidad de agua juega un rol crítico, ya sea en la forma de escurrimiento superficial o como recarga de las napas en la pampa del Tamarugal, especialmente en lo que se refiere a los primeros asentamientos humanos con signos de sedentariedad como son los casos de Ramaditas y Guatacondo. La alta variabilidad intra-anillas en las muestras de Ramaditas indica que hacia los 2600 años se produce un período de transición desde una situación ligeramente menos árida a las condiciones actuales, al tiempo que el incremento de aguas escurridas desde paisajes más altos y una mejor recarga de agua subterránea permitió a los primeros habitantes de Ramaditas mantener extensos campos de cultivos.

Los datos isotópicos sugieren que en los últimos 10000 años la región se fue transformando crecientemente en un paisaje más árido como resultado de la baja humedad de las zonas de recarga en las tierras altas de los Andes hacia el Este de la pampa del Tamarugal. De tal forma que la disponibilidad de agua a través de descargas estacionales o recarga subterránea jugó un rol crucial en las poblaciones que antiguamente se establecieron en esta región.
Nester et al. (2007), estudiando la situación de la quebrada de Chacarilla, ubicada inmediatamente al norte de Guatacondo, destacan que la descarga mayor pudo haberse producido aquí entre 16380 y 13740 cal años b.P. con una descarga menor ocurrida entre 1070 y 700 cal años b.P.

El comportamiento climático esbozado también puede ser interpretado macroespacialmente. Jorge Moya (2006) ha obtenido dos secuencias de 242 y 536 años, respectivamente, tomando como base los sitios de Nasahuento y Guallatire en el altiplano tarapaqueño, a partir de muestras de Polylepis tarapacana Phil. Los estadígrafos resultantes de ambas cronologías señalan que son adecuadas para ser utilizadas con fines dendroclimatológicos. Las funciones de correlación de ambos sitios también muestran que el crecimiento estuvo regulado por precipitación, señalando una correspondencia positiva con el verano previo, en donde los resultados obtenidos son equivalentes a aquellos de sitios estudiados en Bolivia y Argentina, especialmente en Tunupa, Caquella y Soniquera (Argollo et al., 2004) y en cerro Granada en el Nor Oeste de Argentina (Morales et al., 2004; Soliz et al., 2009), lugar este último donde la secuencia se extendió hasta el año 1297 de la Era. Consecuentemente, Polylepis tarapacana está bajo la influencia de una señal macroclimática común para el área en estudio. Esto nos permite proponer una vinculación efectiva entre el altiplano y el área del desierto en relación con las condiciones climáticas en el pasado, demostrando una dinámica similar en ambas regiones posiblemente a través de un largo período.

Es indudable entonces que los recursos ambientales pueden haber estado sujetos a las condiciones más húmedas de las tierras altas que habrían producido descargas hacia la planicie inclinada donde predomina la magnitud del desierto. Recientemente Gayo et al. (2012), sobre la base de evidencia recuperada de quebrada Mani, a 20 kilómetros al sur de Ramaditas, establecen tres períodos, a saber: 1050-680; 1615-1350; 2500-2040 cal años b.P., en que fue posible la ocupación humana gracias a la disponibilidad de agua, coincidiendo con la cronología ya establecida para Ramaditas.

La impronta registrada en las anillas de los árboles puede tener al menos dos causas: 1) natural, relacionada con eventos de la Oscilación del Sur-El Niño (ENSO) u otras condiciones climáticas, y 2) debido a la acción humana. La posible conexión con fenómenos ENSO, en especial en relación con las condiciones climáticas de áreas del desierto 
durante el Holoceno Medio, constituye un tópico sobre el que hay amplia discusión y diversidad de hipótesis (Betancourt et al., 2000; Grosjean, 2001; Rech et al., 2002; Quade et al., 2001; Quade et al., 2008; Williams et al., 2008; Rivadeneira et al., 2009). Últimamente Gayo et al. entregan nuevos resultados sobre la posible incidencia de fenómenos ENSO en la causal de la variabilidad climática en los últimos 2500 años (Gayo et al., 2012: 298).

En relación con la acción humana, es importante tener en cuenta el punto de vista de Dean y Doyel (2006), quienes señalan que tanto procesos naturales como culturales están estructurados sobre la base de variaciones a través de un largo tiempo, de manera que el proceso de adaptabilidad del comportamiento humano así como la variabilidad ambiental debe ser estudiado con amplio criterio temporal. De allí que la interacción hombre-medio ambiente es crucial como objetivo de gran alcance en nuestra investigación.

En estas condiciones es importante enfatizar el contraste de este dilema con la marcada presencia que exhibe la ocupación prehispánica de Ramaditas, en extensos y muy bien elaborados campos de cultivo, una red jerarquizada de canales de irrigación que alimentaban los campos de cultivo y que forma parte de un conjunto de obras hidráulicas que además incluye pozos artesianos, grandes acequias, empozamientos y reservorios; la existencia de formaciones boscosas fósiles en los alrededores del sitio contribuye al planteamiento de una situación hidroclimática especial, así como la importante cantidad y variedad de restos de plantas recuperados a través de polen, restos macrobotánicos, coprolitos y semillas, especialmente las que han sido sometidas a alteración intencional mediante machacado en piedras de moler asociadas al nivel más temprano (Thompson, 2005; Cummings et al., 2005; Rivera, 2002).

Las evidencias señaladas sobre el agua como recurso indispensable en Ramaditas revelan una situación de bastante complejidad donde el registro arqueobotánico pone de manifiesto que las condiciones ecológicas fueron alteradas y manipuladas por el hombre.

En la actualidad la masa forestal de tamarugos se encuentra confinada a unos pocos miles de hectáreas en terrenos privados y del Estado, cubriendo una superficie aproximada de 28.214 hectáreas que incluye la Reserva Nacional Pampa del Tamarugal, lo que permite la búsqueda de material vivo o muerto. Restos de troncos enterrados y semifosilizados encontrados en lugares donde no hay bosque actualmente, nos permite asumir que la extensión cubierta era superior en el pasado, constituyendo un potencial importante para ampliar el área de estudio tanto espacial como temporalmente. Recientes fechados de ejemplares de este bosque relictual han entregado información que retrotrae la existencia de formaciones naturales de tamarugo al menos 7000 años y nos aportarán información crucial para posibles reconstrucciones hidroclimáticas y análisis de variables medioambientales que han marcado el clima en el pasado.

Los resultados que aquí se consignan constituyen un hito importante para la comprensión de la relación hombre-medio ambiente al momento de los primeros asentamientos en la zona más árida del mundo. La continuación de los estudios dendrocronológicos es crucial para llegar a comprender el excelente manejo del paisaje más árido del planeta por un grupo humano que logró establecerse, desarrollarse y producir, transformando un medio hostil en un ambiente favorable.

\section{Agradecimientos}

Este trabajo es resultado de los proyectos "Paleoenvironment and tree ring studies in the Atacama Desert, Northern Chile" y "Dendroarchaeology in the Atacama Desert, Northern Chile", financiados por Nacional Geographic Society (Grants \# 883610, \# 8373-07) y Research and Artistry Grant de CLAS, Northern Illinois University y Fundación Herron (Idabel, Oklahoma), a quienes agradecemos. Igualmente, diversas personas e instituciones han hecho posible esta investigación. Jorge Moya (Universidad Austral de Chile), Raquel Pinto, Ivor Ostojic (Iquique, Chile), estudiantes de Beloit College participantes del Programa Escuela de Campo en Atacama, Amanda Silverman, Grace Smith, Sophie Jones, Aaron Svarlien y Julia Blatchford. A Beloit College, la Fundición Neptuno y sus trabajadores y a nuestros innumerables amigos y colegas en Iquique y Guatacondo que nos han ayudado con logística y conocimiento en nuestro trabajo de campo. Por sobre todo, dedicamos este trabajo a nuestro colaborador y compañero de trabajo Dr. Daniel E. Shea, quien por más de veinte años nos acompañó en las innumerables campañas de terreno, finalmente entregando su vida a este desierto que lo cobijó por largas temporadas, especialmente en las tierras áridas y calientes de Ramaditas. 


\section{Referencias Citadas}

Aravena, R.

1995 Isotope hydrology and geochemistry of northern Chile groundwater. Boletín Instituto Francés de Estudios Andinos 24: 495-503.

2005 Isotope Hydrology of Northern Chile Groundwater. GWADI Oxford Workshop.

Aravena, R. y O. Suzuki

1990 Isotopic evolution of rivers in northern Chile region. Water Resources Research, 26: 2887-2895.

Aravena, R.; O. Suzuki; H. Pena; A. Grilli; A. Pollastri y

H. Fuenzalida

1999 Isotopic composition and origin of the precipitation in Northern Chile. Applied Geochemistry, 14: 89-100.

Argollo, J.; C. Soliz y R. Villalba

2004 Potencialidad dendrocronológica de Polylepis tarapacana en los Andes Centrales de Bolivia, Ecología en Bolivia, 39(1): 5-24.

Baied, C.

2005 Disponibilidad Hídrica y Movilidad en Ecosistemas de Puna Durante el Arcaico-Formativo Temprano en los Andes Centro Sur. En Rivera, M.A., ed. Arqueología del Desierto de Atacama, La Etapa Formativa en el Área de Ramaditas/Guatacondo, Universidad Bolivariana/LOM Ediciones, pp. 63-71, Santiago.

Beresford-Jones, D.; S. Arce; O.Q. Whaley y A.J. Chepstow-Lusty 2009 The Role of Prosopis in Ecological and Landscape Change in the Samaca Basin, Lower Ica Valley, South Coast Peru from the Early Horizon to the Late Intermediate Period, Latin American Antiquity 20: 303-332.

Betancourt, J.L.; C. Latorre; J.A. Rech; J. Quade y K.A. Rylander 2000 A 22,000-Thousand Year Record of Moonsonal Precipitation from Northern Chile's Atacama Desert, Science 289: $1542-1546$.

Bohlke J.K.; G.E. Ericksen y K. Revesz

1997 Stable isotope evidence for an atmospheric origin of desert nitrate deposits in northern Chile and southern California, U.S.A. Chemical Geology 136 (1-2): 135-152.

Boninsegna, J.

1992 South American dendroclimatological records, Climate since A. D. 1500 , editado por R. S. Bradley y P. D. Jones, Routledge, London, 446-462.

Briffa, K.R.

1995 Interpreting high-resolution proxy climate data: the example of dendroclimatology. (Eds H. von Storch and A. Navarra). Analysis of climate variability, applications of statistical techniques, pp. 77-94 Springer, Berlin.

Bryson, R.

2005 Implications of Macrophysical Paleoclimatic Models for Irrigation Agriculture at Ramaditas, Northern Chile, En Rivera, M.A., ed. Arqueología del Desierto de Atacama, La Etapa Formativa en el Área de Ramaditas/Guatacondo. Universidad Bolivariana/LOM Ediciones, pp. 37-62, Santiago.

Christie, Duncan; A. Lara; J. Barichivich; R. Villalba; M. Morales y E. Cuq

2009 El Niño-Southern Oscillation Signal in the world's highest-elevation tree-ring chronologies from the Altiplano, Central Andes, Palaeogeography, Palaeoclimatology, Palaeoecology 281: 309-319.
Clarke, J.D.A.

2006 Antiquity of aridity in the Chilean Atacama Desert. Geomorphology 73: 101-114.

Cummings, L.S.; C. Nepstad-Thornberry y K. Puseman 2005 Restos Paleofecales del Sitio de Ramaditas, Norte de Chile: Aspectos sobre Dieta y Salud en el Formativo Medio y Tardío. En Rivera, M.A., ed. Arqueología del Desierto de Atacama, La Etapa Formativa en el Área de Ramaditas/ Guatacondo, Universidad Bolivariana/LOM Ediciones, pp. 195-210, Santiago.

Dean, J.S. y D.E. Doyel

2006 Culture, Environment, and Adaptation: Perspectives from the Ancient Southwest, Environmental Change and Human Adaptation in the Ancient American Southwest, Dean y Doyel eds pp. 1-9 University of Utah Press.

Di Castri, F. y E. Hajek.

1976 Bioclimatología de Chile. Santiago, Vicerrectoría Académica de la Universidad Católica de Chile. 124 p.

Dodd, J.P.; W.P. Patterson; C. Holmden y J.M. Brasseur

2008 Robotic micromilling of tree rings: a new tool for obtaining subseasonal environmental isotope records, Chemical Geology 252: 21-30. doi:10.1016/j.chemgeo.2008.01.021.

Dodd, J.P. y M.A. Rivera

2012 Variations in groundwater availability during the past 9,000 years in the Atacama Desert, Chile: A subannual record of oxygen isotope values from Prosopis tamarugo tree rings, American Geophysical Union Meeting, H53A1509, San Francisco.

Ericksen, G.E.

1983 The Chilean Nitrate Deposits American Scientist 71: 366-374.

1981 Geology and origin of the Chilean nitrate deposits U.S. Geological Survey Professional Paper 1188, 37 p.

Gajardo, R.

1993 La vegetación natural de Chile. Clasificación y distribución geográfica. Editorial Universitaria, Santiago. 165 pp.

Gayo, E.M; C. Latorre; C.M. Santoro; A. Maldonado y R. De Pol-Holz

2012 Hydroclimate variability in the low-elevation Atacama Desert over the last $2500 \mathrm{yr}$, Climate of the Past, 8, 287-306.

Ffolliott, P. y J. Thames

1983 Manual sobre taxonomía de Prosopis en México, Perú $y$ Chile. FAO, Roma. 31 p.

Fritts, H.C.

1976 Tree Rings and Climate. London, Academic Press. 567 p.

Fuenzalida, H.

1971 Climatología de Chile. Publicación interna de la sección de Meteorología. Departamento de Geofísica y Geodesia, Universidad de Chile. 73 p.

Grosjean, M.

2001 Mid-Holocene Climate in the South-Central Andes: Humid or Dry? Science 292: 2391a.

Grosjean M.; L. Núñez; I. Cartagena y B. Messerli

1997 Mid-Holocene climate and culture change in the Atacama Desert, Northern Chile, Quaternary Research 48: 239-246. IREN

1976 Instituto de Investigaciones de Recursos Naturales. Inventario de Recursos Naturales por Método de Percepción del Satélite LANDSAT. I Región. 
Latorre, C.; J.L. Betancourt y M.T.K. Arroyo

2006 Late Quaternary vegetation and climate history of a perennial river canyon in the Río Salado basin $\left(22^{\circ} \mathrm{S}\right)$ of northern Chile. Quaternary Research 65: 450-466.

Morales, M.; R. Villalba; P. Villagra; J.A. Boninsegna; A. Ripalta

y L. Paolini

2001 Potencialidad de Prosopis ferox Griseb (Leguminoseae, subfamilia: Mimosoideae) para estudios dendrocronológicos en los desiertos subtropicales de alta montaña. Revista Chilena de Historia Natural, 74: 865-872.

Morales, M.R.; H. Villalba; R. Grau y L. Paolini

2004 Rainfall controlled tree growth in high elevation subtropical treelines, Ecology 85(11): 3080-3089.

Mostny, G.

1970 La Subárea arqueológica de Guatacondo, Boletín Museo Nacional Historia Natural 29: 271-287.

Moya, Jorge

2006 Desarrollo de las primeras cronologías de ancho de anillas de Quenoa (Polylepis tarapacana Phil.) en el Altiplano del Norte de Chile, Tesis de Master en Ciencias, Mención Recursos Forestales, Universidad Austral de Chile, Valdivia.

Muñoz, J.; P. Duhart; P. Crignola; G.L. Farmer y C.R. Stern 1997 The mid-Tertiary coastal magmatic belt, south-central Chile. Congreso Geológico Chileno, № 8, Actas, Vol. 3, p. 1,694-1,698. Antofagasta.

Nester, P., E. Gayo; C. Latorre; T.E. Jordan y N. Blanco 2007 Perennial stream discharge in the hyperarid Atacama Desert of northern Chile during the latest Pleistocene, Proceedings National Academy of Sciences 104: 19724-19729.
Nishiizumi, K.; M.W. Caffee; R.C. Finkel; G. Brimhall y G. Mote 2005 Remnants of a fossil alluvial fan landscape of Miocene age in the Atacama Desert of northern Chile using cosmogenic nuclide exposure age dating. Earth Planetary Science Letters 237: 499-507.

Quade, J.; J. Rech y J. Betancourt

2001 Mid-Holocene Climate in the South-Central Andes: Humid or Dry? Response, Science 292: 2391.

Quade, J.; J.A. Rech; J.L. Betancourt; C. Latorre; B. Quade; K.A. Rylander y T. Fisher

2008 Paleowetlands and regional climate change in the central Atacama Desert, northern Chile, Quaternary Research 69: 343-360.

Rech, J.A.; J. Quade y J.L. Betancourt

2002 Late Quaternary paleohydrology of the central Atacama Desert, Chile (22-24 $\left.{ }^{\circ} \mathrm{S}\right)$, Geological Society of America Bulletin 114: 334-348.

Rech, J.A; J.S. Pigati; J. Quade y J.L. Betancourt 2003a Re-evaluation of mid-Holocene deposits at Quebrada Puripica, northern Chile, Palaeogeography, Palaeoclimatology, Palaeoecology 194 (1-3):207-222http://www.sciencedirect. com/science/article/pii/S0031018203002785 - AFF3\#AFF3

Rech, J.A.; J. Quade y W.S. Hart

2003b Isotopic evidence for the source of $\mathrm{Ca}$ and $\mathrm{S}$ in soil gypsum, anhydrite and calcite in the Atacama Desert, Chile, Geochimica et Cosmochimica 67(4): 575-586.

Ramírez de Bryson, L.M.; R.U. Bryson y R.A. Bryson 2001 A paleoclimatic and material cultural perspective on the Formative Periodo f Northern Chile, Chungara 33: 5-12. 